\title{
How the seventh grade students visualize atomic structure and models
}

\author{
Rüveyda Yavuz ${ }^{1, *}$, and Funda Savaşc1-Açıkalın ${ }^{2}$ \\ ${ }^{1}$ Graduate Student, Istanbul University-Cerrahpaşa Graduate School Istanbul Turkey \\ ${ }^{2}$ Associate Professor, Istanbul University-Cerrahpaşa Hasan Ali Yucel Faculty of Education, Istanbul \\ Turkey
}

\begin{abstract}
The purpose of this study is to examine how the seventh-grade students visualize the atomic structure and models in their minds. The problem of the study is "How do the seventh grade students visualize the atomic structure and models?" This study is conducted with 25 seventhgrade students in a state school, Bursa. Qualitative research methodology was adopted in the study. As data collection tools, worksheets were collected via four different activities by the researcher. Data collection process took two weeks (eight lessons). Worksheets consist of different questions about atom and structure and also atom models. For the validity and objective evaluation of the worksheets, an analysis schema was prepared for four different activities by a subject instructor and two science teachers with two or four years teaching experiences. Analysis schema and worksheets were re-evaluated by the science teacher with three years of teaching experiences. Consequently, students' visualization of the atom structures do not match with the scientific models. And also, students confuse the basic concepts about atomic structure.
\end{abstract}

\section{Introduction}

Science requires more thinking and comprehension activity because it contains abstract concepts to understand difficulty [1]. The particulate nature of matter is one of the abstract concepts that need to be learned precisely in chemistry at the elementary level and forms the basis of chemistry education [2]. It is difficult for middle school students to teach atom and structure which is abstract and difficult to learn [3]. Since atoms and atoms models are abstract concepts, it is important to identify how students visualize these concepts in their minds and compare them with the scientific models [4]. Moreover, since they are fundamental concepts, learning them are required for understanding other concepts in science [5]. It is easily seen that students also try to create concepts related to this subject through their own experiences and prior knowledge in their minds [6]. Much information about atomic and structure is on the submicroscopic level, so it is not accessible for direct observation [7].

\footnotetext{
* Corresponding author: fsavasci@istanbul.edu.tr
} 


\subsection{Multiple Representations}

Students should associate three levels of representation, macroscopic, submicroscopic and symbolic, with each other properly in order to develop a scientific understanding of this subject [8]. Macroscopic levels refer to the visible aspects of the material; submicroscopic levels provide information about the atomic, molecular, and kinetic aspects of matter, and also symbolic levels include the use of symbols such as formulas [7]. Students use macroscopic features to explain submicroscopic levels, so they cannot differentiate between macroscopic and submicroscopic ones each other [9]. Thus, students have difficulty to visualize atomic structure and models due to the relationship between multiple representations [10]. Furthermore, they have many misconceptions about these abstract concepts such as atom models, protons, neutrons, electrons, ions and models have been identified in the literature [11-17]. Some of misconceptions are listed in Table 1 and Table 2.

Table 1. Misconceptions about atomic structure

\begin{tabular}{|c|c|}
\hline Misconceptions & References \\
\hline Electrons and protons have the same weight. & Valanides, 2000 \\
\hline Electrons are heavier and smaller than proton. & Olsen,2002 \\
\hline Copper atoms are different from each other. & Olsen,2002 \\
\hline Negative charges in atoms are less than positive charges. & Gilbert et all,2004 \\
\hline Electron and neutron in the nucleus, the proton is in orbit. & Gilbert et all,2004 \\
\hline The atom can be seen under a microscope. & Coll\&Taylor,2007 \\
\hline Atom particles do not move. & Coll\&Taylor,2007 \\
\hline $\begin{array}{l}\text { The atom cannot be broken apart, because the nuclei } \\
\text { cannot be broken. }\end{array}$ & Papageorgiou et al.,2016 \\
\hline Atom is the smallest structure of matter. & Papageorgiou et al.,2016 \\
\hline $\begin{array}{l}\text { If the material is compressed, the shape of the atom } \\
\text { changes. }\end{array}$ & Kapıcı\&Akçay,2016 \\
\hline Atom is alive because the electrons move. & Mishra,2017 \\
\hline Atom is small enough to be visible. & Mishra,2017 \\
\hline Electron and proton in the orbit, neutron in the nucleus. & Fitriza \& Gazali,2018 \\
\hline
\end{tabular}

According to other studies in the literature [9-10], [18-28].on the teaching of atom and structure, limited number of studies are about not only atom and structure but also atom models. And also, they do not include all learning outcomes. For these reasons, it is found to have no effect on the students' learning at the expected level. Thus, this study is important that it includes both the atomic structure and models with considering both the basic knowledge and learning outcomes, as well as multiple representations. Overall, the aim of this study is to examine how the seventh-grade students visualize the atomic structure and models in their minds. And the research question is 'How do the seventh grade students visualize the atomic structure and models?' 
Table 2. Misconceptions about atom models

\begin{tabular}{|c|c|}
\hline Misconceptions & References \\
\hline Atom is square. & Bajah \& Teibo,2000 \\
\hline Atom is moving wave. & Bajah \& Teibo,2000 \\
\hline Atom is straight. & Park \& Light,2009 \\
\hline Atom looks like clouds. & Park \& Light, 2009 \\
\hline $\begin{array}{l}\text { According to the Bohr Atom model, the electrons in the } \\
\mathrm{H} \text { atom move freely in the nucleus and resemble the } \\
\text { Grape Cake model. }\end{array}$ & Kahraman \& Demir, 2011 \\
\hline $\begin{array}{l}\text { According to the Modern Atom model, electrons in the } \mathrm{H} \\
\text { atom are drawn as moving particles in the orbits around } \\
\text { the nucleus and mixed with the Bohr Atom model. }\end{array}$ & Kahraman \& Demir, 2011 \\
\hline $\begin{array}{l}\text { According to the Bohr Atom model, protons are at the } \\
\text { center, and according to Modern Atom model, protons } \\
\text { are distributed in equal amounts everywhere. }\end{array}$ & Kahraman \& Demir, 2011 \\
\hline $\begin{array}{l}\text { Atomic structure resembles the solar system. } \\
\text { Accordingly, the sun is similar to the atomic nucleus, the } \\
\text { planets are similar to electrons, and they act in certain } \\
\text { orbits like electrons. }\end{array}$ & Kapıcı \& Akçay, 2016 \\
\hline $\begin{array}{l}\text { The atom is similar to a globe with a core in it. Like the } \\
\text { Earth, it is round and central. The Moon, which is the } \\
\text { world's satellites, resembles electrons. In this model, the } \\
\text { number of electrons is low and the atomic nucleus and } \\
\text { electron are under the same shell. }\end{array}$ & Kapıcı \& Akçay, 2016 \\
\hline $\begin{array}{l}\text { The atomic structure resembles a spinner, with the } \\
\text { nucleus in the middle and round, with all of the electrons } \\
\text { revolving around this nucleus in a single orbital granular } \\
\text { shape. }\end{array}$ & Papageorgiou et all,2016 \\
\hline Atom looks like the Earth. & Mishra, 2017 \\
\hline Atom is square. & Fitriza \& Gazali, 2018 \\
\hline
\end{tabular}

\section{Methodology}

Qualitative research methodology was adopted in the study [29]. This study is conducted with the 25 seventh-grade students as 10 girls and 15 boys in state school, Bursa. As data collection tools, worksheets were collected via four different activities organized by the researcher. Worksheets consist different questions about atom and structure and also atom models. Data collection process took two weeks (eight lessons).

\subsection{Analysis}

For the validity and objective evaluation of the worksheets, an analysis schema was prepared for four different activities by a subject instructor and two science teachers with two or four years teaching experiences. Analysis schema and worksheets were reevaluated by the science teacher with three years of teaching experiences. 


\section{Findings}

Table 3. Findings about students' models of particles in atom

\begin{tabular}{llllllll}
\hline & & \multicolumn{2}{c}{ Scientific } & \multicolumn{2}{c}{ Partial } & \multicolumn{3}{c}{ None } \\
& & $\mathrm{f}$ & $\%$ & $\mathrm{f}$ & $\%$ & $\mathrm{f}$ & $\%$ \\
\hline Initial & Shape & 16 & $\mathbf{6 4}$ & 6 & 24 & 3 & 12 \\
& Representation & 19 & $\mathbf{7 6}$ & 3 & 12 & 3 & 12 \\
& Space & 13 & $\mathbf{4 2}$ & 6 & 24 & 6 & 24 \\
& Explanation & 2 & 8 & 1 & 4 & 22 & $\mathbf{8 8}$ \\
& Shape & 4 & 16 & 17 & $\mathbf{6 8}$ & 4 & 16 \\
Heated & Representation & 5 & 20 & 15 & $\mathbf{6 0}$ & 5 & 20 \\
& Space & 2 & 8 & 1 & 4 & 22 & 88 \\
& Explanation & 1 & 4 & 1 & 4 & 23 & 92 \\
Bent & Shape & 6 & 24 & 15 & $\mathbf{6 0}$ & 4 & 16 \\
and & Representation & 8 & 32 & 13 & $\mathbf{4 2}$ & 4 & 16 \\
Twisted & Space & 5 & 20 & 1 & 4 & 19 & $\mathbf{7 6}$ \\
& Explanation & 5 & 20 & 3 & 12 & 17 & $\mathbf{6 8}$ \\
\hline
\end{tabular}

As seen in Table 3, students have difficulty in explaining the shape and size of the change in their particles by heating or bending the material. For example, the percent of students who scientifically explain the particles of copper plate before heating is $64 \%$ while the percentage of students who scientifically explain the shape of the particles is $16 \%$ when the copper plate is heated and the percentage of the students who scientifically explain the shape of the particles scientifically when the plate is bent is $24 \%$. And also, percentage of students who scientifically explain the particle size of the copper plate before heating is $76 \%$ while the percentage of the student who scientifically explains the size of the particles is $20 \%$ when the copper plate is heated and $32 \%$ of the students explain the shape of the particles when the plate is bent scientifically. On the other hand, students also often have difficulty explaining the space between particles initial and after the material is heated and bent. Moreover, $42 \%$ of students explain the gap between pre-heated particles of copper plate and the $8 \%$ of students explain the gap between particles when the copper plate is heated and $20 \%$ of students explain the gap between particles when the plate is bent scientifically.

Table 4. Findings about students' design of atom models

\begin{tabular}{lcccccc}
\hline & \multicolumn{2}{c}{ Scientific } & \multicolumn{2}{c}{ Partial } & \multicolumn{2}{c}{ None } \\
& $\mathrm{f}$ & $\%$ & $\mathrm{f}$ & $\%$ & $\mathrm{f}$ & $\%$ \\
\hline Shape & 14 & $\mathbf{6 4}$ & 2 & 8 & 9 & 36 \\
Use of Imagination & 14 & $\mathbf{6 4}$ & 11 & 44 & 0 & 0 \\
Explanation & 3 & 12 & 3 & 12 & 19 & $\mathbf{7 6}$ \\
\hline
\end{tabular}

Table 4 shows that, when asked to design atom models, $64 \%$ of students design scientific models in terms of shapes, while $36 \%$ design non-scientific models. In terms of use of creativity, $64 \%$ of the students used their creativity while designing the model, partially using $44 \%$. And also, $76 \%$ of the students did not adequately explain these atom models.

Table 5. Findings about students' drawings of atomic structure

\begin{tabular}{lllllll}
\hline & \multicolumn{2}{c}{ Scientific } & Partial & \multicolumn{2}{c}{ None } \\
& $\mathrm{f}$ & $\%$ & $\mathrm{f}$ & $\%$ & $\mathrm{f}$ & $\%$ \\
\hline Shape & 7 & 28 & 8 & 32 & 10 & $\mathbf{4 0}$ \\
Name of particle & 7 & 28 & 2 & 8 & 16 & $\mathbf{6 4}$ \\
Color & 3 & 12 & 0 & 0 & 22 & $\mathbf{8 8}$ \\
Mobility & 0 & 0 & 0 & 0 & 0 & 0 \\
Explanation & 0 & 0 & 0 & 0 & 0 & 0 \\
\hline
\end{tabular}


Table 5 revealed that the student who explains shape and particle name scientifically is $28 \%$ while the ratio of students who do not base on scientific explanation is $40 \%$ in shape and $64 \%$ in name of particle. While $88 \%$ of the students are not scientific in their atomic and structure models, only $12 \%$ can be considered scientific. It has been determined that students are not sufficient in general explanations of mobility and so, models about atomic structure seem to be not scientific.

Table 6. Findings about students' atom models

\begin{tabular}{|c|c|c|c|c|c|c|}
\hline & \multicolumn{2}{|c|}{ Scientific } & \multicolumn{2}{|c|}{ Partial } & \multicolumn{2}{|c|}{ None } \\
\hline & $\mathrm{f}$ & $\%$ & $f$ & $\%$ & $f$ & $\%$ \\
\hline Name of Atom Model & 23 & 92 & 2 & 8 & 0 & 0 \\
\hline Name of Scientist & 22 & 88 & 3 & 12 & 0 & 0 \\
\hline $\begin{array}{l}\text { Model Drawing and } \\
\text { Explanation }\end{array}$ & 9 & 36 & 15 & 60 & 1 & 4 \\
\hline $\begin{array}{l}\text { Consistent with } \\
\text { Textbook }\end{array}$ & 16 & 64 & 8 & 32 & 1 & 4 \\
\hline
\end{tabular}

As seen in Table 6 , the atomic models that $92 \%$ of the students made are scientific, not the non-scientific model. Moreover, $88 \%$ of the students state the name of the scientist scientifically. Although $60 \%$ of the students draw the model correctly, they do not base on any scientific explanation. In addition, it is realized that $64 \%$ of the students draw the same models as the models in the textbook.

\section{Discussions}

Based on these findings, students have some misconceptions about atomic structure because the phenomenon of atom is carried out in the submicroscopic level, it is difficult for students to comprehend and to create a mental model [30].Similarly, students cannot explain the atom models properly and they have some misconceptions about the model. Since they use macroscopic features to explain submicroscopic events, so they can not differentiate between macroscopic and submicroscopic ones each other [9]. When the explanations about atomic structure of students are investigated, it is stated that students try to explain the concepts related to this subject through their own experiences and prior knowledge in their minds [31]. Also, in the study of Baybars \& Küçüközer [11] listed that a lot of misconceptions about the topic of atom such as atom models, proton, neutron, and electron.

\section{Conclusion}

It is found that students have difficulty in explaining the space between particles in the case that before and after the material was unheated and bent and twisted. Moreover, it is defined that due to the heating or bending of the material, they have some misconceptions in terms of size and shape such as the adhesion of the atoms to each other and the decrease in the number of atoms. On the other hand, even though most of the students (64\%) design scientific atomic models as shapes, but a large majority (76\%) are not adequately enough to explain these models or explain some misconceptions such as the charge of proton is - and the ones of neutron is + . It is discovered that after the atomic models are introduced to the students, the vast majority (92\%) made atom models scientifically and also although the majority of the drawn models $(64 \%)$ are the same as the visuals in the textbook; they have no scientific knowledge such as what it is or how it is developed. At the end of the research, the following suggestions can be made: 
1. Since there is no difference in conceptual learning of students and it is difficult to change this with a short term, long-term studies should be designed to make difference in conceptual learning of students.

2. Students should make the atom models thanks to student-centered activities.

3. Students should design the atomic structure and models by animating or simulating to learn through experience.

\section{References}

1. A. Ayas, B. Coştu, Yeni Bin Yılın Basında Fen Bilimleri Eğitimi Sempozyumu (İstanbul, 2001)

2. Z. Yaseen, S. Akaygün, Mehmet Akif Ersoy Üni. Eğt. Fak. Der. 40, 469 (2016)

3. G. Demircioğlu, M. A. Aydın, H. Demircioğlu, Bayburt Üni. Eğt. Fak. Der. 6, 70 (2012)

4. G. Tsaparlis, G. Papaphotis, Int. Jour. of Sci. Edu. 31, 895 (2009)

5. M. Duran, B. Balliel, S. Bilgili, $2^{\text {nd }}$ International Conference on New Trends in Education and Their Implications. (Ankara, 2011)

6. D. L. Gabel, Jour. of Che. Edu., 70, 193 (1993).

7. D. L. Gabel, International Handbook of Science Education (London,1998)

8. J. Gobert, L. O'Dwyer, P. Hortwiz, B. Buckley, S. T. Levy, U. Wilensky, Int. Jour. of Sci. Edu. 33, 653 (2011)

9. D. Yeğnidemir, Yüksek lisans tezi. Gazi Üniversitesi. (Ankara, 2000)

10. S. T. Bajah, B. O. Teibo, Senior Secondary Chemistry Book (Longman, 2000)

11. M. G. Baybars, H. Küçüközer, Eği. ve Öğr. Araş. Der., 3, 405 (2014)

12. Z. Fitriza, F. Gazali, F. (2018). Jour. of Phys. Con. Seri, 1013, 87 (2018).

13. R. E. Mayer, R. Moreno, (2002). Edu. Psyc. Rev., 1, 87 (2002)

14. B. Mishra, Int. Jour. of Adv. Res., 5, 1957 (2017)

15. S. Özgür, A. Bostan, E-Jour. of New Wor. Sci. Aca, 3, 214 (2007)

16. G. Papageorgiou, A. Markos, N. Zarkadis, Sci. Edu. Int., 27, 464 (2016)

17. N. Valanides, Che. Edu.: Res. and Pra., 1, 249 (2000)

18. A. K. Griffiths,K. R. Preston, Jour. of Res. in Sci. Teac., 29, 611 (1992)

19. A. G. Harrison, D. F. Treagust, Sci. Edu., 80, 509 (1996)

20. C. Tsai, Int. Jour. of Sci. Edu., 22, 285 (2000)

21. C. Nakiboğlu, Gazi Üni. Eğt. Fak. Der., 21, 131 (2001)

22. R. V. Olsen, Int. Jour. of Sci. Edu., 24, 565 (2002)

23. H. Tezcan, H., Ç. Salmaz, Gazi Üni. Eğt. Fak. Der., 25, 41 (2005)

24. N. Kavak, Gazi Üni. Eğt. Fak. Der., 27, 327 (2007)

25. R. K. Coll, N. Taylor, Res. in Sci. and Tech. Edu., 19, 171 (2001)

26. H. Tezcan, T. Çelik, Türk Eğt. Bil. Der., 7, 49 (2009)

27. E. J. Park, G. Light, Int. Jour. of Sci. Edu., 31, 233 (2009)

28. S. Kahraman, Y. Demir, Erzincan Üni. Eğt. Fak. Der., 13, 173 (2011)

29. J. W. Creswell, Ĕgiten Kitap (Ankara, 2013)

30. F. Kaya, F. (2010). Yayımlanmamış Yüksek Lisans Tezi Pamukkale Üniversitesi (Denizli,2010)

31. H.Ö. Kapıcı, H. Akçay, Euro. Jour. of Edu. Stu., 2, 43 (2016) 